\title{
PERT USING FUZZY VARIABLES AND PROBABILITY DISTRIBUTION FUNCTION RANDOMLY SELECTED
}

Rene A. Santa Cruz Rodriguez Santa Catarina State University Brazil

E-mail: adolfo.rodriguez@udesc.br

Submission: $11 / 06 / 2018$

Accept: 01/07/2018

\section{ABSTRACT}

Program Evaluation and Review Technique (PERT) is widely used for project management in real world applications. The aim of this paper is to simulate and analyze a PERT network under conditions of uncertainty though a hybrid model. The basic assumption is that a project under extreme conditions of uncertainty can be satisfactorily modelled by using simple fuzzy linguistic variables to estimate activities durations, and a probability distribution function randomly selected in order to measure the activity times. Fuzzy linguistic expressions are used to estimate the activity time. Activity parameters are calculated by using basic operations between triangular fuzzy numbers and centroid method with classical Beta PERT definition. For each activity time a probability distribution function is randomly selected from a set of four possible distributions commonly cited in the literature. Hypothetical projects with 4, 40, 400 and 4000 activities using the proposed model are analyzed; the project duration is estimated through Monte Carlo Simulation. Finally, results are analyzed and compared with classical Beta PERT technique.

Keywords: Pert; Fuzzy Sets; Project Management. 


\section{INTRODUCTION}

A project network is a set of activities that must be performed according to a given pre-defined sequence, that is, each activity cannot start until all preceding activities have been completed. When the activity duration times are clear, known and deterministic, the Critical Path Method (CPM) can be used to measure and control de project activities.

Thus, CPM uses one deterministic value for each activity duration time. However, in real world this may not be fulfilled accurately due to the vagueness of activity duration times. To deal with such situations, in the 1950s the Program Evaluation and Review Technique (PERT) was development as a U.S. Navy project based on probabilities (MALCOLM et al., 1959).

In PERT technique, activity durations are defined by stochastic variables and beta distribution is used as a satisfactory model for the activity time distribution. Three numbers are estimated for each activity: optimistic, most likely and pessimistic times. With those three values the expected completion time and variance for each activity are calculated and it is assumed a normal distribution for the project duration (GREENBERG; BEN-YAIR, 2010; HERRERÍAS-VELASCO et al., 2011).

Although PERT is a widely used tool, it received some disagreement concerning its assumptions. In such a way, a non-exhaustive list could refer to the following subjects: proposed activity distribution, activity times, method of determining the parameters and project completion time, three-point estimations, independence of activities, result of the PERT calculation and the omission of the activity calendars (HAJDU, 2013).

In the literature, some authors have proposed many different distributions other than beta, such as the normal distribution, doubly truncated normal distribution, lognormal distribution, the mixed beta and uniform distribution, triangular distribution, parkinson distribution, tilted beta distribution, weibull distribution, mixture distributions (BENDELL, et al. 1995; PREMACHANDRA, 2001; ABDELKADER, 2004; MOHAN, et al., 2007; HAHN, 2008; MCCOMBS, et al., 2009; SHANKAR, et al., 2010; LÓPEZ MARTíN, et al., 2012).

Alternatively, others studies keeps the initial model because it considers that the use of different distributions does not affect significantly the distribution of project 
INDEPENDENT JOURNAL OF MANAGEMENT \& PRODUCTION (IJM\&P)

http://www.ijmp.jor.br

v. 10, n. 1, January - February 2019

ISSN: 2236-269X

DOI: 10.14807/ijmp.v10i1.844

duration, and the principal focus mast be the accuracy of activity time estimations (KAMBUROWSKI, 1997; HAJDU; BOKOR, 2016).

Another approach was developed from the 1970s combining fuzzy sets and PERT technique for measuring imprecision or vagueness in the activity time estimations (CHANAS; ZIELIŃSKI, 2001; CHEN, 2007; CHEN; HUANG, 2007; HSIAU; LIN, 2009; KE; LIU, 2010; LIBERATORE, 2016; GLADYSZ, 2017). In this case, fuzzy numbers may be preferred to probability theory in measuring activity duration uncertainty if the past data are not relevant or are not available or the definition of the activity itself is somewhat uncertain or the notion of completion of the activity is vague (CHEN; HSUEH, 2008; LIBERATORE, 2008).

In this approach, fuzzy variables are used to estimate the activity time, usually a trapezoidal or triangular number represents the range of pessimistic to optimistic variation of time. The minimum and maximum time of project duration is calculated by operations and ranking methods among fuzzy numbers.

The objective of this paper is to simulate and analyze a PERT network under conditions of uncertainty though a hybrid model. The basic assumption is that the project network under extreme conditions of uncertainty can be satisfactory modelled and solved by combining two elements: i) simple linguistic variables to estimate activities durations, and ii) random selection of the probability distributions functions for modelling and measure the project conclusion time. Each activity time is estimated using three linguistic variables expressed by specific triangular fuzzy numbers.

To achieve this goal, the arrangement of this paper is as follows. The research methodology is described in Section 2. Beta PERT Technique and Fuzzy Theory Sets basics are discussed in Section 3. In Section 4 a Hybrid Pert-Fuzzy method is designed, a numerical example is presented and the result is compared with the traditional Beta PERT technique. Finally, same conclusions are drawn in Section 5 .

\section{METHODOLOGY}

In this section, the methodology followed in this paper is described. Firstly, using fuzzy linguistic expressions three times are estimated for each activity: 
optimistic, most likely and pessimistic. The centroid method is used for defuzzification each fuzzy number to get a crisp value of activity time.

Secondly, by using basic operations among fuzzy numbers the mean of the activity time is calculated. The variance of each activity is calculated using the crisp time in accordance with the variance definition of classical Beta PERT technique.

Thirdly, for each activity a random probability density function is assigned from a set of four possible distributions, that is, normal distribution, lognormal distribution, beta distribution and triangular distribution.

Fourthly, the project duration time is estimated using the Monte Carlo Simulation with preselected probability density function. Finally, results are compared with the classical Beta PERT technique.

\section{PERT AND LINGUISTIC VARIABLES}

In the following section, a briefly review of basic definitions of PERT technique and of linguistic variables are described.

\subsection{Pert technique}

PERT is a network based aid for planning, measuring and controlling many interrelated activities in a large and complex project. A project with few activities can be represented graphically to show the precedence or parallel relationships among the activities. Thus an activity occurs when all previous activities have been completed. Figure 1 shows a simple example of project network.

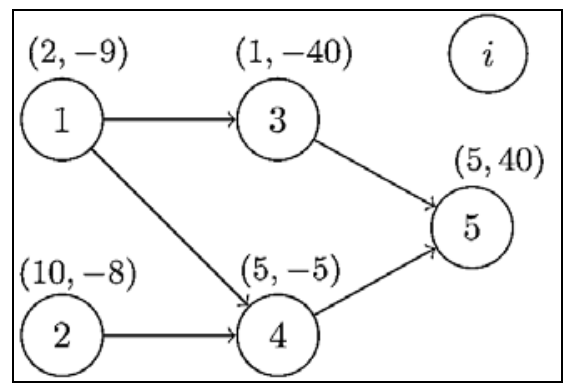

Figure 1: Simple Pert Network

Source: adapted from Hermans; Leus (2018).

In a PERT network, the activity durations are defined by stochastic variables that are assumed to be independent of each other. This method uses beta distribution as an adequate distribution of activity duration, Equation 1 as follows defines this function (SHANKAR, et al., 2010). 


$$
f(x)=\frac{\Gamma(\alpha+\beta)(x-a)^{(\alpha-1)}(b-x)^{(\beta-1)}}{\Gamma(\alpha) \Gamma(\beta)(b-a)^{(\alpha+\beta-1)}} ; a<x<b ; \quad \alpha, \beta>0
$$

The numbers $(a, b)$ are endpoints of the domain of $x$, and $(\alpha, \beta)$ the parameters of the beta distribution. The distribution is identified as Beta PERT if the both parameters are greater than one, in this case, $f(x)$ has one maximum and tends to zero at the endpoints of the domain. In PERT technique, the expected time for each activity can be approximated by the Equation 2 .

$\mu(x)=\frac{(a+4 m+b)}{6}$

The numeric values $\mathrm{a}, \mathrm{m}$ and $\mathrm{b}$ are determined by experts subjectively and represents the "optimistic", "most likely" and "pessimistic" activity times. Figure 2 shows a typical density function of this distribution.

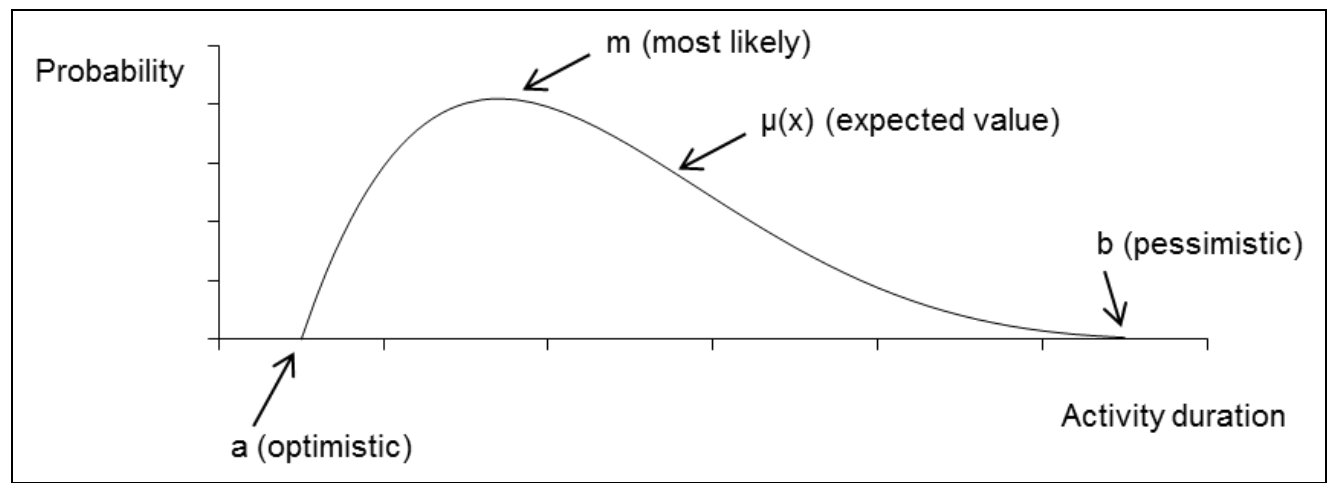

Figure 2: Beta Pert Distribution Function

Source: adapted from Hajdu (2013).

Regarding the variance of each activity time, if three standard deviation times are considered for the pessimistic and optimistic times, then there are six standard deviations between them, as shown in Equation 3.

$\sigma_{x}^{2}=\frac{(b-a)^{2}}{36}$

Optimistic time is generally the shortest time in which the activity can be completed, most likely time is the completion time having the highest probability, and pessimistic time is the longest time that an activity might require.

In original PERT a project duration follow a normal distribution where both the expected value and variance of total project durations are respectively the sum of expected activity durations and variances of activities along the critical path. The estimated project duration time is the longest path thorough the project network, thus 
DOI: 10.14807/ijmp.v10i1.844

activities on the critical path are the ones witch absolutely must be done on time (HAJDU, 2013).

\subsection{Linguistic variables}

In 1970s, the Fuzzy Set theory was developed by Zadeh based on the notions of linguistic variable and fuzzy logic to handle uncertainty that is non-statistical in nature, namely, the intrinsic ambiguity than a statistical variation (ZADEH, 1999). Classical sets contain objects that satisfy absolute precise properties of membership [0 or 1] while the theory of fuzzy set provides the gradual association of elements in a set.

To achieve this task, a membership function value is not precise and it can vary in the real unit interval $[0,1]$ where the endpoints values of 0 and 1 represents not membership and full membership, respectively. Therefore, the main difference is the membership functions; in the first case, a classical set $A$ has a unique membership function $\phi A(x)$, in the second case, a fuzzy set $A$ can have an infinite number of membership functions $\mu A(x)$ to represent it. Figure 3 shows the comparison between crisp and fuzzy concepts (ROSS, 2010).

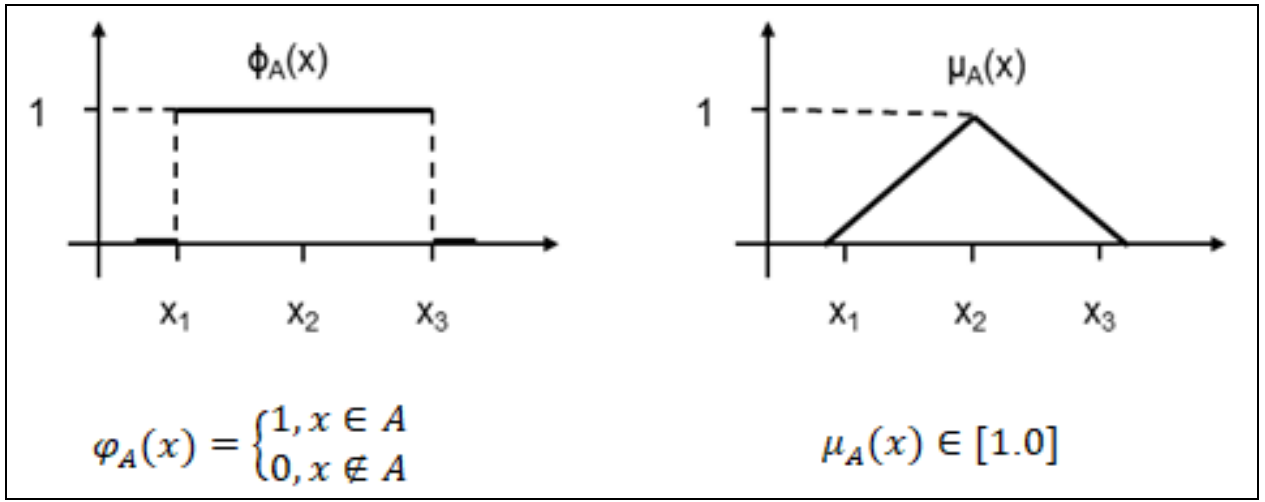

Figure 3: Crisp and Fuzzy concepts.

Source: adapted from Ross (2010).

Thus, a fuzzy set $A$ in $R$ (real line) is defined to be a set of ordered pairs $A=\{(x, \mu A(x)) / x \in R\}$. It is named normal if there is at least one point $x \in R$ with $\mu(x)=1$ and convex if for any $x, y \in R$ and any $\lambda \in[0,1]$, has the following $\mu(\lambda x+(1-\lambda) y) \geq \min \{\mu(x), \mu(y)\}$. A fuzzy number is a fuzzy set on the real line that satisfies these both conditions (NASSERI, 2008). 
Among the various shapes of fuzzy numbers, triangular fuzzy numbers are the most popular ones, it is represented with three points $(a, b, c)$ by the following membership function:

$\mu_{A}(x)=\left\{\begin{array}{cc}0, & x<a \\ \frac{x-a}{b-a}, & a \leq x \leq b \\ \frac{c-x}{c-b}, & b \leq x \leq c \\ 0, & x>c\end{array}\right.$

In addition, $a$ to $b$ is an increasing function, $b$ to $c$ is a decreasing function and the following constraint must be satisfied $a \leq b \leq c$ (GANI; ASSARUDEEN, 2012). In order to analyze the operations between fuzzy numbers, let be $p(p 1, p 2, p 3)$ and $q(q 1, q 2, q 3)$ two triangular fuzzy numbers and $k$ a positive scalar number, the basics fuzzy operations used in this paper are defined as:

$$
\begin{aligned}
& p+q=\left(p_{1}+q_{1}, p_{2}+q_{2}, p_{3}+q_{3}\right) \\
& p * q=\left(p_{1} q_{1}, p_{2} q_{2}, p_{3} q_{3}\right) \\
& k * q=\left(\mathrm{kq}_{1}, \mathrm{kq}_{2}, \mathrm{kq}_{3}\right)
\end{aligned}
$$

The values of linguistic variables are words or sentences in a natural or artificial language. Zadeh defined a linguistic variable by a quintuple $(H, T(H), U, G$, M) where $\mathrm{H}$ is the name of the variable; $T(\mathrm{H})$ is the term set of $\mathrm{H}$ (the collection of its linguistic values); $U$ is a universe of discourse; $G$ is a syntactic rule for the generation of the names of $\mathrm{H} ; \mathrm{M}$ is a semantic rule for associating its meaning with each $\mathrm{H}$, $M(X)$, which is a fuzzy subset of $U(Z A D E H, 1974$; ZADEH, 1975).

The author also defines the linguistic term set by means of a context free grammar, and their semantic as fuzzy numbers described by membership functions. Following this approach, the activity duration can be described using simple linguistic terms, namely, by a fuzzy number, most specifically by a triangular or trapezoidal fuzzy number (ZHANG; LI, 2005).

On the other hand, defuzzification is the process for conversion a fuzzy number to a crisp value. The popular centroid defuzzification method defines the centroid coordinate of $A$ in horizontal axis as it defuzzified value which can be calculated as follow (UEHARA; HIROTA, 1998; WANG; LUOH, 2000).

$x_{0}(A)=\frac{\int x \mu_{A}(x) \mathrm{d} x}{\int \mu_{A}(x) \mathrm{dx}}$ 
Therefore, for a triangular number $A=(a, b, c)$ the centroid is:

$x_{0}(A)=\frac{1}{3}(a+b+c)$

\subsection{A Hybrid Pert Technique}

For simplification purposes, in this section a sequence of $\mathrm{n}$ activities is used to represent the steeps of a simple project network, which has a single critical path as shown in Figure 4.

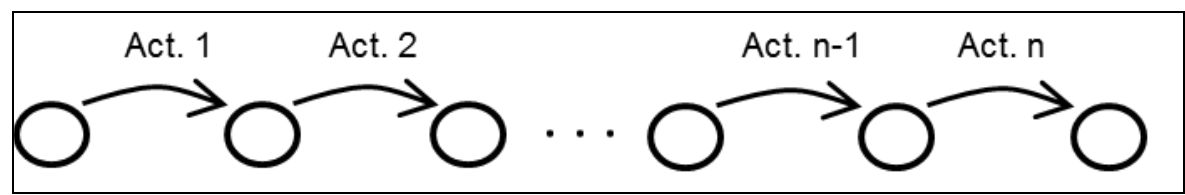

Figure 4: Network activities.

Since the activity duration in a project network is usually very difficult to be determined exactly, fuzzy linguistic expression combined with probability density functions randomly selected are introduced for each of them. In this step, expressions such as "approximately between $x$ and $y$ units of time" were used in order to estimate pessimistic, most likely and optimistic activity times with positive triangular fuzzy numbers as semantics values. Table 1 shows linguistic expression and their fuzzy numbers for a project activity.

According to Equation 5, the average time of this activity was $(11.3,13.67,16)$ hours. In this case, their centroid represents a crisp number of the activity time. As shown in Equation 9 the average time was 13.7 hours. The activity variance was estimated using the Equation 3 with centroids of optimistic and pessimistic times calculated according to the Equation 9, namely, Variance $(x)=6.25$ hours.

Table 1: Linguistic expressions for a project activity time

\begin{tabular}{lc}
\hline Linguistic expression & Fuzzy number \\
\hline Optimistic: approximately between 5 and 9 hours & $(5,7,9)$ \\
Most likely: approximatively between 11 and 13 hours & $(11,12,13)$ \\
Pessimistic: approximatively between 18 and 26 hours & $(18,22,26)$
\end{tabular}

The next step is to determine the activity time behavior. As the basic assumptions are conditions of extreme uncertainty, it is very hard to specify some probability distribution function that can represent the time behavior. Thus, it is assumed that a probability distribution function can be randomly selected for this 
purpose. To this end, a set of probability distribution functions commonly cited in the literature was considered.

Four distributions were assigned for this task, namely, Classic Beta Pert, Lognormal, Normal and Uniform. Therefore, for each activity a probability distribution function was randomly selected from these four alternatives. In each case, distribution parameters were calculated using mean and standard deviations that were obtained in the previous step. A total project time was estimated using Monte Carlo Simulation technique with above given parameters. Calculations have been performed by an application developed in Object Pascal on Linux platform.

Using the hybrid technique a hypothetical project with few activities was initially considered. In this case, a project has the following characteristics: i) only four activities, ii) linguistic variables with symmetric triangular fuzzy numbers, iii) alpha parameters of fuzzy numbers ranging from 5 to $10 \%$ and 5 to $20 \%$ of their centroid value, and iv) each activity has a different probability distribution function. Table 2 shows the activities with fuzzy numbers and probability distribution functions used in Monte Carlo Simulation.

Figure 5 shows the project time after 10000 experiments. The project duration time in the first case was estimated as 167.26 hours and the standard deviation as 5.72 hours while the time, calculated according to the classical Beta PERT, was 166.8 hours and 3.7 hours as standard deviations.

On the assumption that the estimates of experts could be even broader or wider, it was assumed that alpha parameter of linguistic variables could vary randomly between 5 to $20 \%$ with respect to centroid number. In the same way that the above case, simulation results suggest a little difference between project duration with alpha ranging from 5 to $20 \%$ of their centroid number and time obtained using classic Beta PERT technique.

Table 2: Activity parameters

\begin{tabular}{ll}
\hline Description & Activities $[\mathrm{A}, \mathrm{B}, \mathrm{C}, \mathrm{D}]$ \\
\hline Fuzzy activity time $(\mathrm{h})$ & {$[(35,37,39),(9,10,11),(64,70,76),(26,28,30)]$} \\
Optimistic & {$[(41,45,49),(11,12,13),(71,76,81),(31,34,37)]$} \\
Most likely & {$[(43,47,51),(15,17,19),(75,81,87),(40,43,46)]$} \\
Pessimistic & {$[(39.7,43.0,46.3),(11.7,13.0,14.3),(70.0,75.7,81.3)$,} \\
Mean & $(32.3,35.0,37.7)]$ \\
& {$[2.78,1.36,3.36,6.25]$} \\
Variance & {$[$ Normal, Uniform, Lognormal, Triangular $]$} \\
Probability distribution function &
\end{tabular}


This result shows an expected behavior: if the period between $\mathrm{x}$ and $\mathrm{y}$ values in expert linguistic expression is wide for estimate pessimistic, most likely and optimistic activity times, then the final project duration will have a major impact.

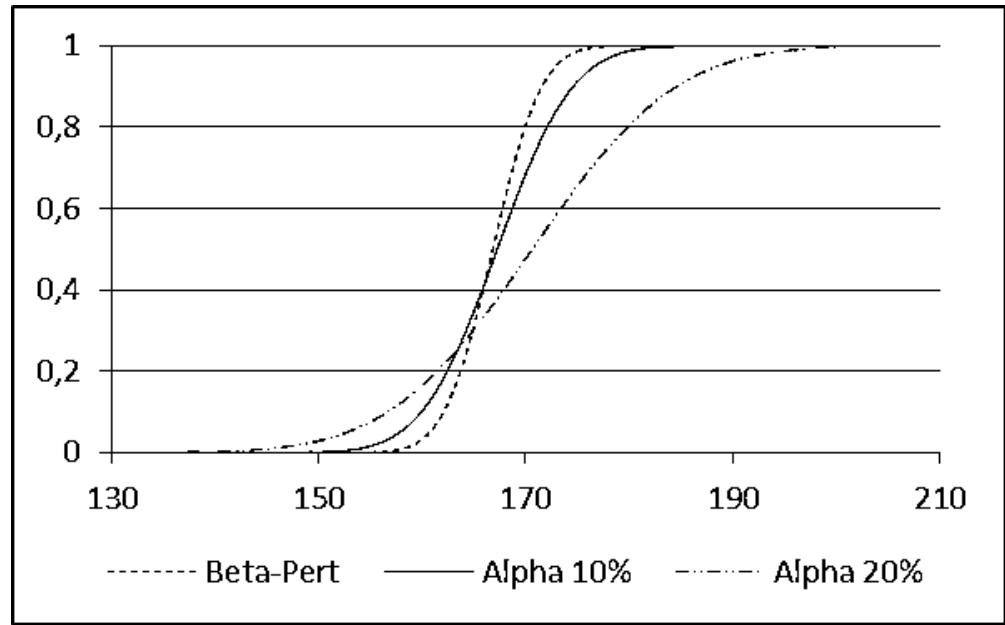

Figure 5: Project evaluation with four activities.

In order to analyze the effects on project with higher number of activities, three other hypothetical examples were considered with the following characteristics: i) number of activities 40, 400, and 4000, ii) linguistic variables with symmetric triangular fuzzy numbers, iii) alpha parameter of fuzzy numbers ranging from 5 to $10 \%$ and 5 to $20 \%$ of their centroid number, and iv) each activity is associated with a probability distribution function randomly selected from a set of probability distribution functions.

In this case, estimation of activity times was obtained by Monte Carlo simulation. Triangular numbers are generated varying randomly from 10 to 200 hours for pessimistic, most likely and optimistic times. In the same way, the time between parameters of triangular fuzzy numbers for pessimistic, most likely and optimistic times were generated randomly from 2 to 5 hours.

Alpha values were also estimated by simulations, in the first case between 5 and $10 \%$ and in the second case varying between 5 to $20 \%$ of the centroid number. Again, for each activity a probability distribution function was randomly selected from a set of preselected probability distribution functions.

Figure 6 shows the results of a project with 40 activities. Simulation process suggest that the difference between the project time using this hybrid model and the results obtained by the traditional Beta Pert can be considered acceptable because 
INDEPENDENT JOURNAL OF MANAGEMENT \& PRODUCTION (IJM\&P)

http://www.ijmp.jor.br

v. 10, n. 1, January - February 2019

ISSN: 2236-269X

DOI: 10.14807/ijmp.v10i1.844

they show little difference. Although the project completion time of the simulations has shown similar values, there are much larger differences among standard deviations. The standard deviation using Beta Pert technique shows lower values compared with those obtained with the proposed hybrid method.

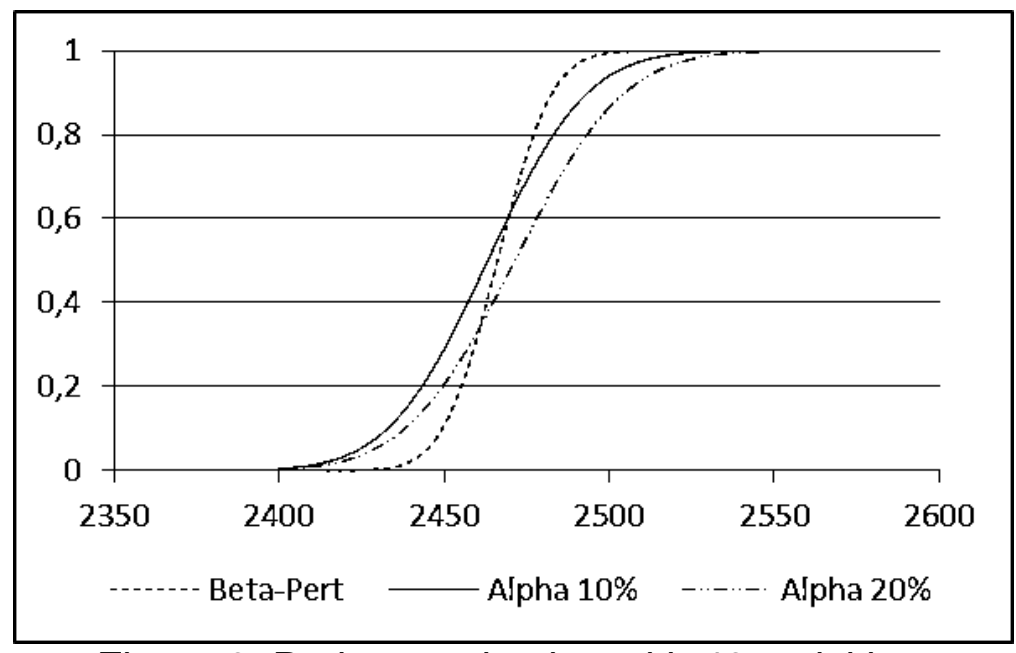

Figure 6. Project evaluation with 40 activities.

Figure 7 shows the next case, an artificial project network is simulated with 400 activities. Results of the experiment confirm the previous case. In three simulations, the project completion time were relatively close and do not show many variations in their values. However, it is observed that the standard deviations show similar behavior to the previous case, the value obtained by the classic Beta Pert was lower compared to the other numeric values. When the alpha parameter of linguistic variable is greater, the standard deviation of the project completion time is also higher.

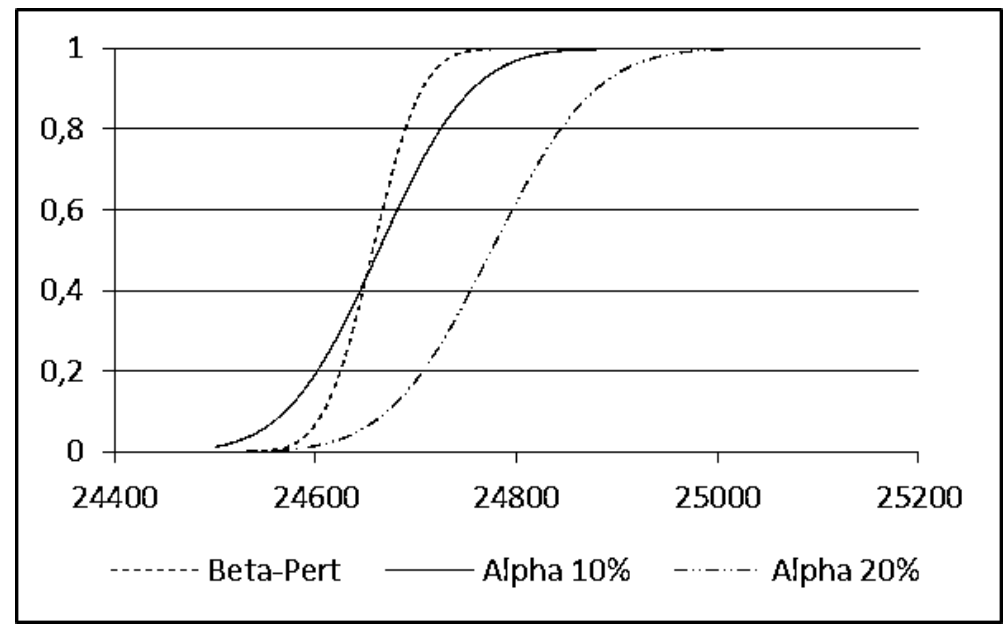

Figure 7. Project evaluation with 400 activities. 
Finally, an artificial project network with 4000 activities was analyzed. The results, shows in the Figure 8 , seem to confirm the previous cases. Project completion time using classical Beta Pert present lower value compared with hybrid model, but this variation is relatively small around $1 \%$. However, the behavior of the standard deviation is something different. The standard deviation calculated with the classic Beta PERT is smaller than the hybrid method with parameters alpha ranging up 5 to 10 and $20 \%$.

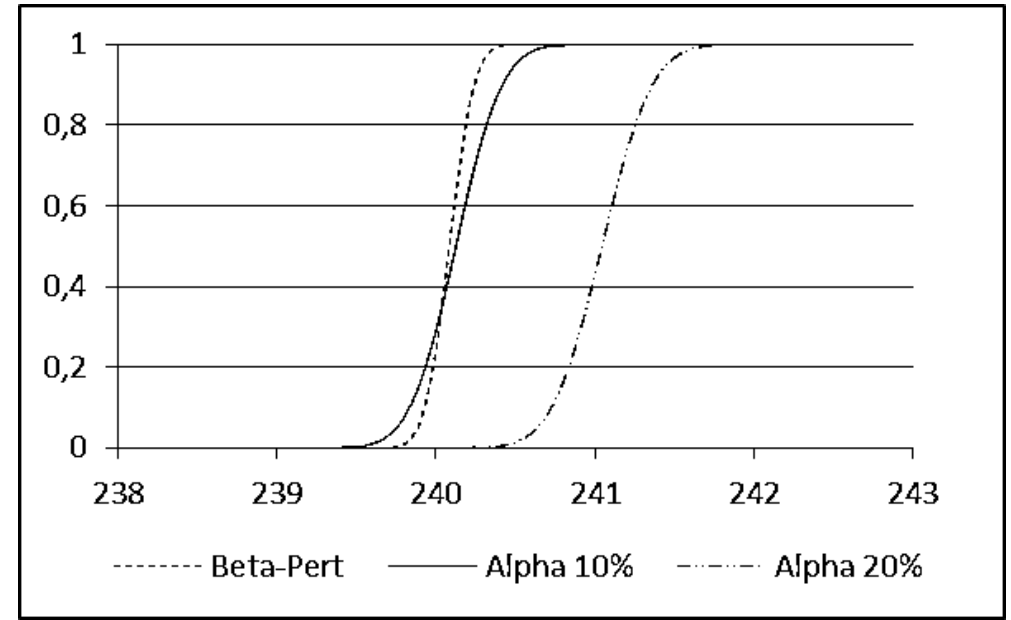

Figure 8. Project evaluation with 4000 activities.

\section{CONCLUSIONS}

Beta PERT technique is widely used for management and control projects in real world applications. In PERT technique the activity duration is defined by a stochastic variable and uses a beta distribution as sufficient model to represent its activity time.

In this paper, it was assumed that the project under extreme conditions of uncertainty can be satisfactory modelled using simple linguistic variables, for estimating durations of activities, and probability distributions functions randomly selected for the project conclusion time.

After 10000 experiments with an artificial project network with 4, 40, 400 and 4000 activities, the results suggest that the completion time obtained from a proposed hybrid model compared with a classical Beta PERT is not much different. On the other hand, standard deviation value of the project time with classical Beta PERT present some variations from those obtained with hybrid model; the higher the alpha value of the parameter of the linguistic variables, the higher is the standard deviation of project completion time. 
The results show that regardless of the number of project activities, when a project is under extreme conditions of uncertainty it can be satisfactory modelled and solved using simple linguistic variables and probability distribution function randomly selected. In this case, fuzzy variables can be used to estimated activities duration times and probability distribution function can be used for modelling the project conclusion time.

Therefore, when it is not possible to determine a probability function that represents the time activity behavior, it seems possible randomly select a probability distribution function from a set of alternatives, which not affect significantly the final result. In this regard, it is noted that the size of linguistic variables end points has a greater impact on the standard deviation of the final result, which leads to considerer that the variability of the project completion time is more affected by the accuracy of the linguistic estimators of activity times.

\section{REFERENCES}

ABDELKADER, Y. H. (2004) Evaluating project completion times when activity times are Weibull distributed. European Journal of Operational Research, v. 157, n. 3, p. 704-715. DOI: 10.1016/S0377-2217(03)00269-8.

BENDELL, A.; SOLOMON, D.; CARTER, J. M. (1995) Evaluating Project Completion Times When Activity Times are Erlang Distributed. Journal of the Operational Research Society, v. 46, n. 7, p. 867-882. DOl:10.2307/2583969.

CHANAS, S.; ZIELIŃSKI, P. (2001) Critical path analysis in the network with fuzzy activity times. Fuzzy Sets and Systems, v. 122, n. 3, p. 195-204. DOI: 10.1016/S0165-0114(00)00076-2.

CHEN, S. P. (2007) Analysis of critical paths in a project network with fuzzy activity times. European Journal of Operational Research, v. 183, n. 1, p. 442-459. DOI: 10.1016/j.ejor.2006.06.053.

CHEN, C. T.; HUANG, D. F. (2007) Applying fuzzy method for measuring criticality in project network. Information Sciences, v. 177, n. 12, p. 2448-2458. DOI: 10.1016/j.ins.2007.01.035.

CHEN, S. P.; HSUEH, Y. J. (2008) A simple approach to fuzzy critical path analysis in project networks. Applied Mathematical Modelling, n. 32, p. 1289-1297. DOI: 10.1016/j.apm.2007.04.009.

GANI, A. N.; ASSARUDEEN, S. N. M. (2012) A new operation on triangular fuzzy number for solving fuzzy linear programming problem. Applied Mathematical

Sciences, n. 6, p. 525-532.

GLADYSZ, B. (2017) Fuzzy-probabilistic PERT. Annals of Operations Research, n. 258, p. 437-452. DOI: 10.1007/s10479-016-2315-0. 
GREENBERG, D.; BEN-YAIR, A. (2010) Beta-Distribution Models in Stochastic Project Management. Computer Modelling and New Technologies, v. 14, n. 4, p. 14-18.

HAHN, E. D. (2008) Mixture densities for project management activity times: A robust approach to PERT. European Journal of Operational Research, v. 188, p. 450-459. DOI: 10.1016/j.ejor.2007.04.032.

HAJDU, M. (2013) Effects of the application of activity calendars on the distribution of project duration in PERT networks. Automation in Construction, n. 35, p. 397404. DOI: 10.1016/j.autcon.2013.05.025.

HAJDU, M.; BOKOR, O. (2016) Sensitivity analysis in PERT networks: Does activity duration distribution matter? Automation in Construction, n. 65, p. 1-8. DOI: 10.1016/j.autcon.2016.01.003.

HERMANS, B.; LEUS, R. (2018) Scheduling Markovian PERT networks to maximize the net present value: New results. Operations Research Letters, n. 46, p. 240244. DOI: 10.1016/j.orl.2018.01.010.

HERRERÍAS-VELASCO, J. M.; HERRERÍAS-PLEGUEZUELO, R.; VAN DORP, J. R. (2011) Revisiting the PERT mean and variance. European Journal of Operational Research, v. 210, n. 2, p. 448-451. DOI: 10.1016/j.ejor.2010.08.014.

HSIAU, H. J. R.; LIN, C. W. (2009) A fuzzy pert approach to evaluate plant construction project scheduling risk under uncertain resources capacity. Journal of Industrial Engineering and Management, v. 2, n. 1, p. 31-47. DOI:

10.3926/jiem..v2n1.p31-47.

KAMBUROWSKI, J. (1997) New validations of PERT times. Omega, International Journal of Management Science, v. 25, n. 3, p. 323-328. DOI: 10.1016/S03050483(97)00002-9.

KE, H.; LIU, B. (2010) Fuzzy project scheduling problem and its hybrid intelligent algorithm. Applied Mathematical Modelling, v. 34, n. 2, p. 301-308. DOI:

10.1016/j.apm.2009.04.011.

LIBERATORE, M. J. (2008) Critical Path Analysis With Fuzzy Activity Times. IEEE Transactions on Engineering Management, v. 55, n. 2, p. 329-337. DOI: 10.1109/TEM.2008.919678.

LIBERATORE, M. J. (2016) A counterexample to the forward recursion in fuzzy critical path analysis under discrete fuzzy sets, International Journal of Fuzzy Logic Systems, n. 6, p. 53-62. DOI: 10.5121/ijfls.2016.6204.

LÓPEZ MARTÍN, M. M.; GARCÍA GARCÍA, C. B.; GARCÍA PÉREZ, J.; SÁNCHEZ GRANERO, M. (2012) An alternative for robust estimation in project management. European Journal of Operational Research, v. 220, n. 2, p. 443-451. DOI: 10.1016/j.ejor.2012.01.058.

MALCOLM, D. G.; ROSEBOOM, J. H.; CLARK, C. E.; FAZAR, W. (1959) Application of a Technique for Research and Development Program Evaluation. Operations Research, v. 7, n. 5, p. 646-669. DOI: 10.1287/opre.7.5.646.

MCCOMBS, E. L.; ELAM, M. E.; PRATT, D. B. (2009) Estimating Task Duration in PERT using the Weibull Probability Distribution. Journal of Modern Applied Statistical Methods, v. 8, n. 1, p. 282-288. 
MOHAN, S.; GOPALAKRISHNAN, M.; BALASUBRAMANIAN. H.;

CHANDRASHEKAR, A. (2007) A lognormal approximation of activity duration in PERT using two time estimates. Journal of the Operational Research Society, $v$. 58, n. 6, p. 827-831. DOI: 10.1057/palgrave.jors.2602204.

NASSERI, H. (2008) Fuzzy Numbers : Positive and Nonnegative, International Mathematical Forum, v. 3, n. 36, p. 1777-1780.

PREMACHANDRA, I. M. (2001) An approximation of the activity duration distribution in PERT. Computers \& Operations Research, n. 28, p. 443-452. DOI: 10.1016/S0305-0548(99)00129-X.

ROSS, T. J. (2010) Fuzzy logic with engineering applications. UK: John Wiley \& Sons.

SHANKAR, N. R.; RAO, K. S. N.; SIREESHA, V. (2010) Estimating the Mean and Variance of Activity Duration in PERT. International Mathematical Forum, v. 5, n. 18, p. 861-868.

UEHARA, K.; HIROTA, K. (1998) Parallel and multistage fuzzy inference based on families of a-level sets. Journal of Information Science, n. 106, p. 159-195.

WANG, W-J.; LUOH, L. (2000) Simple computation for the defuzzifications of center of sum and center of gravity. Journal of Intelligent and Fuzzy Systems, n. 9, p. 5359.

ZADEH, L. A. (1974) The Concept of a Linguistic Variable and its Application to Approximate Reasoning. In Fu, K.S. et al. (eds.), Learning Systems and Intelligent Robots, p. 1-10.

ZADEH, L. A. (1975) The concept of a linguistic variable and its application to approximate reasoning-I. Information Sciences, n. 8, p. 199-249.

ZADEH, L. A. (1999) Fuzzy Sets as a basis for a theory of possibility. Fuzzy Sets and Systems, v. 100, n. 1, p. 9-34.

ZHANG, H.; TAM, C.M.; LI, H. (2005) Modeling uncertain activity duration by fuzzy number and discrete-event simulation. European Journal of Operational Research, n. 164, p. 715-729. DOI: 10.1016/j.ejor.2004.01.035. 